\title{
SOCIEDADE E A CONSTRUÇÃO DO PENSAMENTO GEOGRÁFICO. ENSAIOS ANALÍTICOS E PROPOSITIVOS ${ }^{1}$
}

\author{
Eider Cavalcante ${ }^{2}$
}

\section{Resumo}

$\mathrm{Na}$ atual conjuntura de crise social o conhecimento científico também se apresenta em crise, assim, o pensamento geográfico, não estando aquém das demais ciências e da própria sociedade, encontra-se cotidianamente sendo questionado e debatido, com o intuito constante da apreensão dos novos e velhos paradigmas sociais. Neste contexto procura-se discorrer sobre o pensamento geográfico, abordando suas origens, concepções, base metodológica e evolução. Faz-se uma viagem à história da Geografia a fim de sua inteligibilidade epistemológica, buscando a relação entre a construção do saber e o contexto histórico social, para assim, poder compreender a crise teórica vivenciada nos dias atuais e por fim ensaiar alguns questionamentos a cerca dos "novos" rumos tomados pela ciência Geográfica.

Palavras-chave: Geografia, Sociedade, paradigmas.

\begin{abstract}
In the current conjuncture of social crisis, the scientific knowledge is also present in crisis, so, the geographic thinking, not below of other sciences and society itself, is continuously questioned and debated, with the constant intention in the seizure of new and old social paradigms. In this context it aims to discuss the geographic thinking, covering its origins, concepts, methodological basis and development. It is a trip to the history of Geography to their epistemological intelligibility, seeking the relationship between the construction of knowledge and the social historical context, so, to be able to understand the theoretical crisis experienced today and finally tested some questions about the "new" courses taken by science
\end{abstract} Geographic.

Keywords: Geography, society, paradigms.

\section{Introdução}

\footnotetext{
1 Trabalho oriundo a partir dos debates ocorridos no grupo de estudos e de atuação política sobre o pensamento de David Harvey e Henri Lefebvre. Tratando-se de um primeiro questionamento teórico não apenas individual, mas coletivo, que motiva os membros deste grupo a tentar compreender pensamento destes dois autores.

${ }^{2}$ Graduando do Curso de Geografia da Universidade Estadual do Ceará e bolsista do Programa de Educação Tutorial - PET. Email: eidercavalcante@hotmail.com.
} 
Parte-se do suposto de que a construção do saber é um constructo social e não está aquém da trama societária presente, ainda mais, a sociedade e o saber, especificamente o geográfico, estão internalizados e imbricados um no outro. Portanto o pensamento geográfico apenas torna-se inteligível dentro da realidade social na qual historicamente está inserida. Fazendo-se necessário, então, uma releitura histórica da Geografia e da própria sociedade para compreendermos o que fazíamos e o que fazemos, pois só assim podemos construir um saber geográfico realmente desvelador das máscaras sociais.

Neste ensejo, desejar-se-á compreender o atual contexto do pensamento geográfico em sua busca incessante pela compreensão da sociedade e de seu espaço, que a cada dia se apresenta de forma mais complexa e escamoteada. Sendo lançado então um extenuante desafio de compreender o que foi, o que é e que rumos o pensamento geográfico está tomando, principalmente no âmbito brasileiro que possui grandes avanços e que por vezes deixamos de lado em nossos trabalhos ao passo que axaltamos as teorizações européias ${ }^{3}$.

Neste contexto, não se pode fazer uma historicização do pensamento geográfico em um caráter evolucionista, como se uma escola do pensamento literalmente limasse outra da história, pois mesmo quando uma vertente do pensamento prepondera sobre outra, muitas vezes essa ultima não deixa de existir.

\section{Geografia na história e a história da geografia}

A construção do saber Geográfico teve sua gênese muito antes de sua institucionalização, que só ocorrerá no final do século XVIII. Foi com a civilização sumeriana que o mundo conhecera a primeira representação cartográfica do mundo, datada de 2.700 anos antes da era cristã, construindo-se assim as primeiras referências geográficas da cultura ocidental.

\footnotetext{
3 A geógrafa Sandra Lencioni teve, em sua brilhante obra Região e Geografia, um grande interesse em sistematizar o pensamento geográfico antes de sua institucionalização, pois sabemos que a Geografia tem uma sistematização recente no âmbito europeu. Todavia, ainda existe uma lacuna no que consiste a sistematização do saber espacial (Moraes, 1988) no Brasil antes do surgimento do Curso de Geografia na USP, pois se a transformação da natureza, mediada pelo trabalho, produz o espaço, existe uma saber espacial na história da humanidade. Assim, lançamos a importância de uma sistematização do pensamento geográfico, antes de sua institucionalização, também no âmbito nacional. Tratando-se de um esforço que extrapola as possibilidades deste artigo, se restringindo, então, a focalizar a especificamente a Geografia brasileira principalmente nos atuais debates epistemológicos do conhecimento Geográfico.
} 
O maior legado da antiguidade referente as ciências de modo geral e ao conhecimento geográfico foi dado pelos gregos, pois tal conhecimento, naquele momento histórico, era de importância sin ne qua nom para os mesmos, devido a sua própria estrutura social, sua constante busca pela expansão territorial e pelo fato da intensificação das atividades comerciais e de colonização da época.

Afirmação amparada por Pereira (2006):

\begin{abstract}
Na Grécia "democrática", escravista, onde eram evidentes os desníveis sociais, o determinismo geográfico legitimava as contradições, a expansão e a dominação mercantil e militar e a própria concepção grega de mundo, onde a existência de dominantes e dominados seria tão normal quanto a ocorrência de espaços naturais diferenciados. A presença de uma "ordem hierárquica" social estaria relacionada à "ordem hierárquica ambiental", admitindo-se a existência de lugares privilegiados "superiores" e de espaços "inferiores" destinados a serem explorados em prol do engrandecimento dos primeiros, assim como ocorre na hierarquia social. (PEREIRA, 2006, p. 32)
\end{abstract}

Sobre a importância dos gregos na construção do saber geográfico Lencioni(2003) afirma que:

\begin{abstract}
Aos gregos pode ser creditada a primeira regionalização, por ter sido concebida com algum método. As descrições passaram a ter forma ordenada, sugerindo comparações. Sínteses e explicações foram elaboradas acerca dos lugares e itinerários. Formam eles que criaram a palavra Geografia, em que geo significava terra e grafia, descrever. Concebiam uma Geografia em que cada ponto era considerado em relação ao mundo habitado e denominavam da corografia as descrições das diferenças e contrastes da terra. (LENCIONI, 2003, p. 35).
\end{abstract}

Importante destacar a ligação da descrição com a construção do saber geográfico, ficando atrelada à compilação de itinerários de viagens que descreviam detalhadamente os lugares pelo qual se passava. Ligação essa que perdurou e perdura, em maior ou em menor grau, na Geografia até os dias atuais, significando em alguns momentos a análise geográfica em si e em outros significou/significa um importante aparato nesta análise.

$\mathrm{Na}$ Idade Média pouco se produziu e desenvolveu o pensamento geográfico, como as demais vertentes do saber, por conta da realidade social apresentada no momento, onde, por conta da soberania da Igreja Católica, praticamente todos os estudiosos e pensadores desta época deixaram de lado as observações da natureza e a experimentação. A maior parte dos estudos foi dedicada a teologia e a filosofia, onde os estudiosos, que praticamente se resumiam aos clérigos, tinham pouco ou nenhum interesse pelo conhecimento da natureza.

No tocante a representação cartográfica na Idade Média Carvalho observa que:

Entre os séculos II e o VI da era cristã, a representação do mapa-múndi desapareceu de cena, retornando numa forma muito diferente e redefinida de acordo com o Cristianismo. Pelo fato da Bíblia ter sido considerada o padrão para a reinterpretação da História e do Mundo, os mapamúndi obedeceram à descrição do Gênesis da divisão do mundo entre os três filhos de Noé, daí três continentes. (CARVALHO, 2001, p.01) 
Ainda segundo a autora, as poucas representações cartográficas desligada do aspecto religioso foram alguns itinerários escritos pelos marinheiros da época clássica e elaborados a partir das observações feitas ao longo das costas navegadas, porém não tinham um sistema de coordenadas latitudinais e longitudinais, mas sim uma rede de loxodromas (linhas de rumo) como uma rosa-dos-ventos. E alguns raros trabalhos de influência Ptolomaica, como os de Al Idrisi (c. 1154), Martellus(1489 . 1490) e o de Girolamo Ruscelli (1561).

O conhecimento geográfico só tomou um novo fôlego no período das grandes navegações, que segundo Numa Broc apud Lencioni foi um período em que se modificou o intuito dos itinerários de viagens, "não se tratando mais de obras destinadas a preencher a curiosidade dos homens, mas voltadas a instrumentalizar conquistas e dominações." (LENCIONI, 2003, p. 64).

Com o impulso dado com a criação e consolidação dos impérios coloniais e com as várias necessidades nascidas com a Revolução Industrial, já no final do século XVIII, o pensamento geográfico toma uma grande força, pois se precisava conhecer novos lugares para garantir recursos naturais e econômicos para o desenvolvimento dos países europeus. A Geografia apresenta-se com um aparato instrumental e ideológico neste processo tomando força e reservando seu lugar ao lado das demais ciências, referindo-se aqui a sua institucionalização ${ }^{4}$.

Muitas vezes somos levados literalmente a confrontar os pensamentos dos deterministas e dos possibilistas, como se fossem pensamentos antagônicos em sua completude, esquecendo-se os meandros comuns entre essas correntes. Os próprios termos que distinguiram a escola Francesa e Alemã, entre possibilistas e deterministas, foram cunhadas por Lucien Febvre ${ }^{5}$ em sua obra La Terre et L'Évolution Humaine de 1922. Segundo Sanguin apud Haesbaert (2002):

\footnotetext{
Paul não é contra Ratzel. A suposta oposição entre Vidal e Ratzel não passa de uma montagem intelectual operada por seus discípulos, como Jules Sion e Camille Vallaux, assim como pelo historiador Lucien Febvre. Há relações freqüentes e amigáveis com o geógrafo alemão e sua posição frente à Politische Geographie é acadêmica e nuançada, como testemunha o artigo de fundo publicado nos Annales em 1898. (HAESBAERT , 2002, p.02)
}

\footnotetext{
${ }^{4}$ Segundo Lencioni (2003) o conhecimento geográfico apareceu como disciplina particular de ensino em Königsberg como nome de Geografia Física, tendo sido inaugurada por Emmenuel Kant, que se dedicou a disciplina de 1756 á 1796.

5 Sobre o assunto ver Moreira(1989), Moraes (1990), Haesbaert (2002) e Lacoste( 2002).
} 
O próprio La Blache publicou um artigo denominado de "Geografia política a propósito dos escritos de Friedrich Ratzel”, onde vai debater a sua Geografia Humana (Geografia Política) a partir dos escritos de Ratzel. Mesmo com algumas diferenças teóricas, ele lança vários elogios ao geógrafo alemão, desfacelando, assim, a suposta disputa entre os ditos possibilistas e deterministas.

Referente a primeira corrente, as obras Ratzel, baseando-se fortemente nas teorias em Darwin, principalmente no tocante da "seleção natural das espécies", em parte, tomaram bastante expressividade. Segundo Lencioni (2003) Ratzel considerava que o homem, como uma espécie entre os seres vivos, procura ampliar seu território a custa dos vizinhos. Partindo da idéia de que as condições naturais condicionavam as formas de vida, chegou a conclusão de que os agrupamentos humanos, quando se vêem face a um território limitado, buscavam ampliar seu espaço de vida, mesmo em detrimento dos seus vizinhos. Consubstanciando-se assim uma de suas principais teorias, a teoria do "espaço vital", que foi usada para legitimar as ações imperialistas de expansão alemã. Podendo-se visualizar o caráter instrumental e ideológico do saber geográfico de tentar justificar, viabilizar e legitimar os acontecimentos naquele momento histórico.

No entanto, diante do contexto de tensão internacional, precisavam-se formular idéias a fim de justificar a tradição colonial dos países europeus, assim as idéias "possibilistas" surgem demonstrando que o meio exercia influência sobre o homem, mas que o homem tinha possibilidades de modificar o meio. Pensamento que foi de grande valia ao governo francês, pois acabava por dar um total apoio referente à melhor orientar as políticas e dar todo um aparato ideológico, cerne do desenvolvimento de uma teoria que destacava a superioridade da raça branca sobre as nativas da Ásia e da África, confundindo-se assim interesse colonial com interesses humanitários e civilizatórios. (ANDRADE apud GONÇALVES, 1982)

A partir das discussões acima levantadas pode-se perceber de forma clara que o mundo está vivendo os momentos que antecediam a Primeira Guerra Mundial, sendo esses debates entres possibilistas e deterministas preponderantes até o fim da Segunda Grande Guerra Mundial. Podendo-se então visualizar as causas, objetivos, meios e conseqüências das guerras, além de perceber a função estratégica da geografia neste contexto, que nada tinha de neutra. Parafraseando Lacoste (2002) a geografia serve antes de mais nada para fazer a guerra, fazendo referência a uma geografia aparentemente neutra de cunho simplesmente decorativo e

\footnotetext{
6 Título original: La Géographie Politique a propos des écrits de Frédéric Ratzel. Publicado na revista Annales de Géographie no ano de 1898.
} 
de um valor inútil, apresentada nas escolas, denominada por ele de "Geografia dos Professores", que mascarava uma outra Geografia estratégica e prática que se estabelecia como instrumento político e de ação no domínio da superfície terrestre, chamada de "Geografia dos Estados Maiores".

Com o fim da Segunda Grande Guerra e com a bipolarização do mundo, em um bloco capitalista e outro dito socialista, o contexto social remete novamente a novas mudanças na construção do saber geográfico. "As ciências do espaço ganham dentro desse contexto, de disputas de áreas de influência entre dois sistemas rivais, uma enorme importância" (GONÇALVES, 1982, p. 105).

Neste contexto surge a "revolução teorético-quantitativa", com grande influência da matemática, da estatística e do positivismo lógico, influência essa que se deu em várias ciências, pois com a guerra fria, onde estava embutida a corrida armamentista, guerra espacial, etc. precisava-se como nunca das ciências, a fim de fomentar as intenções políticas dos países engajados. Fato que se deu com alto investimento estatal, mascarado pela suposta neutralidade da ciência.

\begin{abstract}
as teorias locacionais, de difusão de inovações e de pólos de desenvolvimento, deveriam abrir espaço para a expansão das transnacionais para a periferia do sistema capitalista notadamente a partir de $2^{\circ}$ metade da década de 50 , quando o capital internacional preocupado com a luta de libertação dos povos dos povos subordinados, se propõem a "salvar o mundo livre" do subdesenvolvimento, eliminando a miséria, "solo fértil para a inseminação de ideologias estúpidas. (GONÇALVES, 1982, p. 109)
\end{abstract}

Neste contexto, novamente amparando-se em Gonçalves (1982), destacamos a importância da realidade social e a construção do saber geográfico, quando ele destaca:

\footnotetext{
Não foi coincidência que o determinismo geográfico começou a ser criticado ás vésperas da primeira guerra mundial, quando as disputas imperialistas se exacerbavam, nem o fato de ter sido o possibilismo uma reação da escola francesa contra a escola alemã. Também não foi pura coincidência o fato da "visão" regional que substitui a ecológica se firma as vésperas da segunda guerra mundial. Ou ainda, que a "visão espacial" se torne hegemônica quando a "ameaça comunista ao mundo livre", representada pela socialização dos países do leste europeu, exigia uma "teoria" da localização a fim de alocar capitais que o Plano Marshall dirigia ao velho continente. (GONÇALVES, 1982, p. 108)
}

Em paralelo a geografia teorética, que prepondera na década de 50 em boa parte do mundo, surge na França um grupo denominado "Geografia Ativa" que vem ao ataque da geografia regional, ainda forte na França. O grupo que tinha como membros nomes como Lacart e Pierre George, já tratavam temas como subdesenvolvimento, industrialização, entre outros. Porém Gonçalves (1982) faz ressalvas ao dizer que ao tratar esses temas, não se 
preocupavam com os processos, como da divisão internacional do trabalho, mas se amparavam em muitos dados para comparar suas teses.

Em meio a uma realidade tensa de disputa hegemonia e de grandes avanços tecnológicos, com toda uma ideologia desenvolvimentista, as grandes massas, principalmente de países periféricos, não viam as benesses desses avanços, pelo contrário, a cada dia a opressão e a exploração se davam com maior intensidade.

Movimentos de libertação nas colônias dos países europeus, lutas por soluções dos problemas sociais, movimentos que questionavam a degradação ambiental, lutas pela redemocratização (caso brasileiro), eram deflagradas pelo mundo a fora, movimentos esses que ganharam um ar de esperança com a derrota americana no Vietnã e com as lutas estudantis em maio de 68.

Importante neste momento fazer ressalvas sobre os protestos de maio de 68, no contexto europeu, que são alvo de inúmeras polêmicas em torno de seu caráter revolucionário, principalmente por ter sido uma movimentação bastante heterogênea, insurgindo ao mesmo tempo movimentos comunistas de influência Stalinista, movimentos anarquistas, movimentos que apenas questionavam valores como sexualidade e prazer e até movimentos de extrema direita, que mesmo sendo de influência anti-comunista eram contra o governo da época. Contudo, não se questiona a importância ou a essência dos protestos de maio de 68 , carecendo de um aprofundamento maior para tal, mas coloca-se em debate a insurreição dos movimentos fragmentários que surgiram após o fim destes protestos.

Neste contexto Gonçalves (2001) caracteriza os movimentos fragmentários:

... os movimentos que emergem na década de 60 partem da situação concreta de
vida dos jovens, das mulheres, das "minorias" étnicas, etc. para exigir mudanças
dessas condições. É como se observássemos um deslocamento espacial do plano
temporal (História, futuro) para o espacial (o quadro da vida, o aqui e o agora).
(GONÇALVES, 2001, p. 12)

Os movimentos como o ecológico, negro, feminista, homossexual, entre outros, tem bandeiras importantes de lutas, porém são movimentos de bandeiras que acabam por esvair em si mesmas pelo fato de particularizarem por demais as lutas, acabando por enfraquecer o movimento como um todo, além do que, essas bandeiras cotidianamente são levantadas com o intuito de escamotear outros interesses que nada tem a ver com a causa posta em questão. Esses movimentos que emergiram pós 68 deram o tom para movimentos outros que esqueceram as características comuns e se assentaram nas particularidades e que atualmente se exacerbam de tal forma que hoje a luta chega apenas ao "EU", ou seja, emancipação do indivíduo, que é nada mais do que um constructo da ideologia capitalista. 
Neste mesmo contexto, pós maio de 68, observa-se na Europa, principalmente na França, o distanciamento das ciências humanas de modo geral para com vertente estruturalista do marxismo que influenciava as escolas do pensamento da época. Mas só com o nascimento da revista Antinpode (1969-EUA) e da Herodote (1976-França) um pensamento crítico na geografia começa a se propagar pelo mundo, recuperando pensamentos esquecidos pela geografia como o de Reclus (1830-1905), um geógrafo anarquista já engajado em uma concepção crítica e dos próprios membros da Geografia Ativa, que mesmo não sendo de vertente marxista tinham um cunho crítico. Fato que levou o Filósofo François Dosse, em seu livro A história do Estruturalismo, a colocar o título de um dos capítulos de: "A Geografia, essa convidada de última hora". ${ }^{7}$

Essas revistas, em conjunto com as revistas brasileiras, como o Boletim Paulista de Geografia e a Revista Terra Livre, que nas palavras de Gonçalves (1982) eram as armas de guerrilha contra o grande exército de livros e outras mídias financiadas da Geografia teorético-quantitativa, tiveram um papel importante na propagação e na afirmação dessa nova vertente da Geografia.

Põe-se em questão tanto a crítica epistemológica, quanto a crítica ideológico-política da Geografia, porém essa última só fora feito pela geografia de cunho marxista (geografia radical), pois outras vertentes que surgiram, principalmente de base fenomenológica eram críticas as bases epistemológicas da ciência geográfica calcada até então no raciocínio lógico e no Positivismo. Todavia essa geografia de cunho fenomenológico com base subjetiva e que prega o relativismo, presente nos dias atuais, é diferente das idéias iniciais, principalmente proferidas por Husserl, que segundo Lencioni (2003):

O objetivo, perseguido por Husserl foi fundar uma nova base racional para a ciência, buscando captar a essência das coisas por meio da compreensão que nega o subjetivismo e o relativismo, afirmado o mundo vivido com possibilidade de viver a experiência sensível e simultaneamente poder pensá-la de forma racional. (LENCIONI, 2003, p. 150).

A geografia Crítica radical vem literalmente fazer a crítica a essa sociedade capitalista e as próprias teorias das classes dominantes formuladas pela geografia no âmbito nacional e internacional. Presencia-se neste momento uma mudança histórica, no contexto teóricopolítico da Geografia, pois pela primeira vez a mesma retira de si as amarras do Estado e a ideologia dominante e passa a questionar as mazelas sociais e a sua posição histórica como legitimadora das mesmas.

\footnotetext{
${ }^{7}$ Apud Ariovaldo Umbelino de Oliveira no prefácio do livro “Geografia e Filosofia” de Eliseu Savério Spósito.
} 
No Brasil já vinham ocorrendo movimentos em ebulição desde 1974, contudo, apenas "movimentos de mudança" isolados que aos poucos começam a se articular, por conta da necessidade de mudança e aglutinação de idéias que precipitassem a crise da ciência (MOREIRA, 1982).

O contexto brasileiro propiciava bem essas ebulições, pois quanto mais a ditadura oprimia, mais as movimentações cresciam, como as greves operárias por todo o país. Era "época de contestação", onde o próprio maio de 68, anteriormente citado, no cerne do contexto europeu, teve no Brasil e na América Latina conotações bem diferentes, pois além da contestação cultural, os protestos também foram motivados pela luta contra o subdesenvolvimento econômico e contra as ditaduras militares, que oprimiam quase todos os países da América Latina. Em 1968, Brasil, Peru, Bolívia, Paraguai e Argentina estavam sob o comando de Ditaduras e logo depois Uruguai (1971) e Chile (1973) também foram comandadas por essa forma de governo que se caracterizava pela sua intolerância, opressão e repressão social.

O contexto social, o importante papel da AGB, a volta dos exilados políticos ao Brasil, dentre eles o geógrafo Milton Santos, o aparato teórico oferecido por Lacarte, Quaini, Peet, Lefebvre, pelo próprio Milton Santos e por outros pensadores engajados em transformar a Geografia, proporcionaram a convergência desses movimentos no ano de 1978 no $3^{\circ}$ ENG em Fortaleza e formação de teorias que discutiam o espaço e sua produção desigual e desvelando as mazelas sociais, deixando de lado o apoio do Estado e das classes dominantes.

Peet Apud Silva (2000) defende que foi através do marxismo estruturalista que o estruturalismo entrou na Geografia, principalmente através de Louis Althusser, Manuel Casteslls e através dos trabalhos de Lipietz. Esses pensadores influenciaram e influenciam muitos Geógrafos no âmbito nacional e internacional.

Em nome do questionamento ao positivismo, o empírico foi por muito tempo praticamente expurgado da Geografia e os geógrafos influênciando-se pela visão estruturalista construíram suas teorias gerais de análise do espaço calcadas no economicismo, onde a realidade era engendrada sob uma combinação de estruturas econômicas.

Martins (1996) afirma que várias faculdades brasileiras abriram espaço para a invasão de vulgarizadores do marxismo, tratando-se de um marxismo estruturalista de influência althuseriana, reduzindo-o a uma coleção insuficiente de fórmulas e idéias de pouca orientação dialética.

Hoje, não faltam críticas a essa corrente na geografia, onde da mesma forma em que se critica a negação total da geografia de influência positivista, estão deixando também de lado 
todos os avanços advindos como a geografia critica, esquecendo-se até das próprias evoluções da mesma, no contexto em que já superou muitos de seus obstáculos.

\section{Novos paradigmas?}

Pós-maio de 68, com a insurreição dos movimentos fragmentários; com o desvirtuamento da União Soviética, no contexto do Stalinismo, e com sua trágica dissolução; e no contexto brasileiro, com o enfraquecimento das mobilizações após a conquista do direito do voto; muitas coisas começaram a mudar na Geografia. Percebendo-se que a própria involução dos movimentos libertários enfraqueceu a vertente contestadora da Geografia e da ciência como um todo. Um período marcado não pelo fim das desigualdades sociais, que por sinal só aumentaram, mas por um período de generalização da alienação social, principalmente depois da década de 70 com o neoliberalismo.

Segundo Hélio Evangelista $(2000 ; 2006)$ vivemos num admirável e assustador mundo novo, não sendo mais permitido esperança, onde o importante hoje é o aqui e o agora. E segundo Marinho (2008) a pós-modernidade vem para quebrar o falso utopismo da emancipação da sociedade, onde agora reinaria a iniciativa da emancipação do indivíduo.

Os estudos vêm sendo voltados para as micro-relações e para as particularidades, sem conexão com o global, onde os fatos são estudados por si mesmos, muitas vezes com um psicologismo exacerbado, onde quase nunca passam da dimensão do político-cultural. ${ }^{8}$

O pós-modernismo, segundo Jameson apud Spósito (2004), como forma geral de pensamento representa:

\footnotetext{
...uma tendência antitotalizante, antigeneralizante, no tocante à sociedade, rejeitando não tanto a narrativa per se, mas todos os tipos de narrativas grandiosas... optando, em vez disso, por uma abordagem descentralizada, caótica mesmo, da sociedade, que é vista como inteiramente fragmentada. (SPÓSITO, 2004, p. 132)
}

Ventura (2004), que ao defender um pós-modernismo de oposição, afirma que o discurso pós-moderno é adequado para a realidade européia, mas é imprópria para os países subdesenvolvidos e que "a celebração da fragmentação, da pluralidade e da proliferação das periferias oculta a relação desigual, central no capitalismo moderno, entre o Norte e o Sul.” (VENTURA, 2004, p.12). Destacando, ainda, que a declaração do fim das metanarrativas e das totalidades hierárquicas representa, ela mesma, uma metanarrativa cuja totalidade e hierarquia se insinuam na celebração da fragmentação e da diferença.

\footnotetext{
${ }^{8}$ Afirmação oriunda dos trabalhos produzidos nacionalmente.
} 
Considerando-se que, nos dias atuais, com a economia mundializada os processos sociais se dão em escalas mundiais, no cerne de suas causas e conseqüências. Assim, defendese que as afirmações em torno da fragmentação e do relativismo apenas teriam "validade", e assim são feitas, se as análises forem feitas do particular pelo particular, análise essa que se perde em si mesma ao relacionarmos com a primeira afirmação. Assim, defende-se que o discurso pós-moderno também é inviabilizado nas análises do contexto europeu e quisá para entendermos os países subdesenvolvidos. ${ }^{9}$ Como analisar o particular (local) de forma independente se ele sofre, além de impor suas determinações, interferências do externo (Global)?

Enquanto a moda é a própria concepção de uma análise somente no âmbito das particularidades, às relações sociais de produção ficam cada vez mais globais, sendo a própria visão parcelaria da realidade de um fruto gerado por essas relações gerais, por suas mediações locais e sua materialização no espaço. A realidade é fugidia ou as aparências lançadas são parciais, fruto da própria alienação ideológica do capitalista sob a construção do ser?

Para Jameson apud Spósito "há uma falta de profundidade em boa parte da produção cultural contemporânea, quanto a sua fixação nas aparências, nas superfícies e nos impactos imediatos que, com o tempo não têm sustentação", baseando-se na tese de que "o pósmodernismo não é senão a lógica cultural do capitalismo avançado" e continua ao dizer que "abandonar inteiramente o conceito de progresso, no sentido mais geral da possibilidade de emancipação humana possível, implicaria apenas submeter-se aos desejos dos poderes constituídos" e por fim diz que o "desengajamento político de intelectuais de esquerda na época atual só poderia significar uma coisa: obediência total ao capitalismo". (SPÓSITO, 2004, p. 131)

Novamente citando Evangelista (2006), que diz que a história está a exigir novas formas de se aprender o real. Todavia, mesmo acreditando que existem novos paradigmas a serem discutidos, eles estão incrustados nos velhos paradigmas sociais. Será que a fragmentação dos movimentos reivindicatórios, a exacerbação do individualismo, o fim da moral e a da ética e todos os males contemporâneos, são novos paradigmas? Tudo isso é distinto dos velhos paradigmas do modo de produção capitalista, que influência a dimensão social-econômico-político-cultural, hoje, principalmente por conta do neoliberalismo e a reestruturação do capital?

\footnotetext{
${ }^{9}$ O contexto brasileiro, também, se caracteriza como importante fato para questionarmos a existência de "novos" paradigmas, pois os Geógrafos brasileiros precisam sempre associar as teorias ao empírico e não simplesmente exportar teorias oriundas de outras realidades e de outros contextos.
} 
Evangelista (2006) ainda destaca que "não temos mais discernimento, somos guindados feito gado ou sonâmbulos", mas coloca-se outra pergunta: vamos seguir os novos e velhos paradigmas ou vamos tentar transformá-los? A Geografia está voltando novamente a suas bases de submissão a realidade social que está imposta?Seria esse o legado histórico do conhecimento geográfico?

\title{
Em busca do elo perdido
}

Como já foi dito anteriormente, a Geografia de cunho estruturalista não dá conta da trama societária atual, mas se ela for negada em nome de um admirável mundo novo, a ciência geográfica dará um passo secular para trás e irá tranquilamente se atar as amarras que levou bastante tempo para se desprender.

Alguns pensadores estão engajados em superar o estruturalismo e não aderir a "onda" pós-moderna, procurando ir além do economicismo e focalizando no desenvolvimento desigual da sociedade em todas suas escalas e dimensões.

Eyles apud Johnston (1986) defende a idéia de que:

\begin{abstract}
...embora "nem a Geografia ou nenhuma ciência social possa ser completa sem o marxismo", isto é insuficiente. Ela precisa focalizar o mundo experiência, o micromundo da família, das relações, da comunidade, da vizinhança, se quer ser completa, isto requer a interações do marxismo estruturalista com as filosofias humanísticas. (JOHNSTON, 1986, p. 259)
\end{abstract}

Silva (2004) procura fazer um caminho parecido ao tentar unir o materialismo histórico, oriundo do marxismo, com o que ela chama de princípios Nietschianos:

\footnotetext{
Queremos, nesse trabalho, acentuar a importância da dialética materialista, como método das Ciências Sociais em geral e chamarmos a atenção para uma possível ampliação dessa forma de pensar o mundo e trabalharmos, cientificamente com a introdução de alguns princípios nietzschianos, voltados à psicologia do indivíduo, no temário das relações sociais. (SILVA, 2004, p. 42)
}

Para a autora o método marxista só chega as necessidades "primárias sociais", assim, com essa proposta ela tenta enxergar também "o que o homem faz para se auto-afirmar, para encobrir sua pobreza íntima" (SILVA, 2004, p. 51). Sendo hora de, sem enveredar por um psicologismo, considerarmos também as dores e as paixões da emoção humana.

Uma gama de pensadores, como os mencionados acima, vem se engajando em articular teorias gerais estruturalistas, que menosprezam as particularidades, com as teorias das micro-relações que desprezam as relações globais. 
Não querendo exacerbar o purismo metodológico, observa-se um caminho perigoso desta proposta de articulação de teorias, pois as teorias são engendradas dentro de contextos, necessidades e intenções, por vezes contraditórias e/ou até antagônicas. Aparando-se em Neto (2008) ao afirmar que método é antes de tudo uma escolha de vida, escolha essa política. Podendo-se assim questionar Silva (2004): Como articular Marx, onde toda sua teoria tem antes de tudo o caráter revolucionário de emancipação humana, com Nietzsche, onde a própria autora reconhece que passa um pessimismo assustador de como se nada tivéssemos o que fazer?

Mas onde se encontra a verdadeira dialética?O pensamento marxista estruturalista não pode ser considerado o marxismo em si, fato que leva muitos autores até chamar o próprio Marx de estruturalista, relação essa no mínimo anacrônica. Um reencontro com a verdadeira dialética se mais que necessário, pois só assim podemos compreender, em meio a essa complexa e escametoeda trama societária, os novos e velhos paradigmas sociais.

No Brasil muito já se desenvolveu o pensamento geográfico pós sua renovação, datada do final da década de 70, com o trabalho de alguns grupos de pensadores que estão à procura da reconciliação da Geografia com a verdadeira dialética, que foi perdida no desenrolar da história, pela Geografia e pelas demais ciências humanas. Buscando um reencontro com o próprio Marx e como os seus contemporâneos que conseguiram, sem vulgarizar suas teorias, evoluir o seu pensamento e visualizar o que ele não poderia ter visto naquele momento histórico. Tudo isso, sem perder de vista a realiza brasileira que se caracteriza como um verdadeiro filtro para as teorizações.

A Geografia precisa realmente se apropriar da verdadeira dialética, onde a sociedade e o seu espaço são apreendidos na dimensão social-econômico-político-cultural, na articulação contínua, de caminho de ida e volta, entre o local e o global, observando-se desde a captura da subjetividade dos atores sociais da história até os processos globais de reprodução do capital. Só assim podemos construir uma geografia que dê conta dos novos e velhos paradigmas sociais na construção de uma Geografia da práxis que efetivamente atue na transformação do espaço e da sociedade.

\section{Referências bibliográficas}


CARVAlHO, M. S. . O Pensamento Geográfico Medieval e Renascentista no Ciberspace. In: Rosely Sampaio Archela; Tânia Maria Fresca; Rosana Figueiredo Salvi. (Org.). Novas Tecnologias. 1 ed. Londrina: EDUEL, 2001, v. 1, p. 101-113.

EVANGELISTA, Helio de Araujo. A geografia crítica no Brasil. Revista da Faculdade de Filosofia, Ciências e Letras de Duque de Caxias ( RJ ), Duque de Caxias ( RJ ), v. 2, p. 18-34, 2000 .

Geografia crítica. Revista geo-paisagem. Ano 5, no 9, 2006.

GONÇALVES, Carlos Walter Porto. A Geografia está em Crise. Viva a Geografia, in: MOREIRA, Ruy. Geografia: teoria e crítica: o saber posto em questão. Petrópoles: Vozes, 1982.

Os (des) caminhos do meio ambiente. $8^{\mathrm{a}}$ ed. - São Paulo: Contexto, 2001.

HAESBAERT, R. . La Blache, Ratzel e a "Geografia Política". Geographia, Niterói, v. 7, p. 117-121, 2002.

JOHNSTON, R.J. Geografia e Geógrafos: a geografia humana anglo-americana desde 1945. Tradução de. Oswaldo Bueno Amorim Filho. São Paulo: DIFEL, 1986.

LACOSTE, Yves. A geografia - isso serve, em primeiro lugar, para fazer a guerra. $6^{\mathrm{a}}$ ed. Tradução de Maria Cecília França. São Paulo: Papirus, 2002.

LENCIONI, Sandra. Região e Geografia. São Paulo: Edusp, 1999.

MARINHO, Cristiane Maria. Ética e Pós-modernidade. Palestra proferida no Centro Cultural Banco do Nordeste, 2008.

MARTINS, José de Souza. Henri Lefebvre e o Retorno à Dialética. São Paulo: Hicitec, 1996.

MORAES, A. C. R. (org.). Ratzel. São Paulo: Atica,1989.

Annablume 1988.

Ideologias Geográficas. Política, espaço e cultura no Brasil, São Paulo:

. O que é Geografia. São Paulo: Brasiliense, 1989.

MOREIRA, Rui. Pensar e ser em geografia: ensaios de história, epistemologia e ontologia do espaço geográfico. São Paulo: Contexto, 2007

NETO, Manoel Fernandes de Sousa. Por um convite ao método. Palestra proferida no Mestrado Acadêmico em Geografia, 2008.

PEREIRA, Maria Flortice Raposo. A geografia no pensamento filosófico. Mercator Revista de Geografia da UFC, ano 05, número 10, 2006.

SANTOS, Boa Ventura. Do pós-moderno ao pós-colonial. E para além de um e outro. Conferência de Abertura do VIII Congresso Luso-Afro-Brasileiro de Ciências Sociais, 
realizado em Coimbra, de 16 a 18 de setembro de 2004. Disponível em: <www.ces.uc.pt> Acesso em 10/11/08.

SPÓSITO, Eliseu. Geografia e filosofia: contribuição para o ensino do pensamento geográfico. São Paulo: Editora da UNESP, 2004.

SILVA. Carlos Nunes. O pós-positivismo na geografia humana. IN: Finisterra: Revista Portuguesa de geografia. - Vol. XXXV, $\mathrm{N}^{\mathrm{o}} 69$ (2000), p. 151- 154. Disponível em: http://www.ceg.ul.pt/finisterra/numeros/2000-69/69_08.pdf (Acesso dia 03/11/08)

SILVA, Lenyra Rique. Do senso comum à Geografia Científica, São Paulo:Editora Contexto, 2004.

VIDAL DE LA BLACHE, P. A geografia política a propósito dos escritos de Friedrich Ratzel. Tradução: Rogério Haesbaert e Sylvain Souchaud. Niterói: Programa de PósGraduação em Geografia - UFF, 2002. 